\title{
Proteins Pre-concentration Using Glycidyl Methacrylate-co-stearyl Methacrylate-co- ethylene Glycol Dimethacrylate Monolith
}

\author{
Ahmed Ali Alkarimi ${ }^{1{ }^{*}}$ and Kevin Welham ${ }^{2}$ \\ ${ }^{1}$ Department of Chemistry, College of Science, University of Babylon, Hilla 51002, Iraq \\ ${ }^{2}$ Department of Chemistry, Faculty of Science and Engineering, University of Hull, \\ Cottingham Road, Hull HU6 7RX, United Kingdom
}

* Corresponding author:

tel: $+964-7803717179$

email: sci.ahmed.alkarimi@gmail.com

Received: September 16, 2019

Accepted: December 4, 2019

DOI: $10.22146 /$ ijc. 49479

\begin{abstract}
Solid-phase extraction technique is considered as a vital tool in a pretreatment of different samples. Therefore, it was used as a beneficial and alternative extraction method over the liquid-liquid extraction in diverse applications such as food, environmental, and biological analyses. Glycidyl methacrylate-co-stearyl methacrylateco-ethylene glycol dimethacrylate (GMA-co-SMA-co-EDMA) monolithic sorbent was prepared as strong cationic-reversed phase sorbent for solid-phase extraction of different proteins. The monolithic sorbent was prepared inside two moulds such as glass microchip device and borosilicate. The morphological properties have been investigated using the Brunauer-Emmett-Teller (BET) model analyzer and scanning electron microscope (SEM), and the formation of the monolithic sorbent was examined using the FT-IR. Eight proteins (cytochrome $C$, insulin, myoglobin, lysozyme, $\beta$-lactoglobulin, trypsin, albumin chicken egg white, and apo-transferrin) with different molecular weight and isoelectric point were investigated for pre-concentration using the SCX/RP sorbent. It was found that the highest extraction recovery was obtained with three proteins cytochrome $C$, lysozyme, and myoglobin compared with the other proteins. These three proteins were chosen for pre-concentration using the glass microchip. Sorbent performance showed significant results in terms of stability and reproducibility.
\end{abstract}

Keywords: stearyl methacrylate; solid-phase sorbent; glycidyl methacrylate; extraction

\section{- INTRODUCTION}

Solid-phase extraction was used as a beneficial and alternative extraction method. Therefore, it has been used in laboratories for concentrating and purifying different samples. In addition, it could be used for cleaning-up or isolating a wide range of analytes in the matrices such as animal tissue, blood, beverage, water, urine and soil [1-3].

Liquid-solid extraction media were invented in the mid of 1970s. Meanwhile, the extraction methodology was published firstly in 1998. Since then, many further developments have been applied to form the SPE cartridges or disks in addition to newer sorbents, such as molecularly imprinted polymers (MIPs), and immunosorbents (IMs) [4]. Similar to the developments in the sorbent and materials, the solid phase extraction technique over the last few years has been developed and modified, toward automation and miniaturization. According to the Environmental Protection Agency (EPA), this technique has been accepted and used for more than two decades as an alternative procedure for sample preparation over the liquid-liquid extraction technique for the determination of various organic compounds in waste and drinking water [5-6].

The principle of SPE is based on a partitioning of a sample between the liquid mobile phase and the solid stationary phase. Therefore, the extraction occurs when the sample has a high affinity for the solid phase compared with the sample matrix. The samples will be retained on the solid phase and can be eluted at a later stage using an appropriate solvent(s) that has a higher affinity for the sample in the desorption step [7]. The intermolecular forces between the sample and the active 
sites on the sorbent surface, besides, the solid phase nature (hydrophobic RP, hydrophilic NP, ion-exchange IE) could determine the retention mechanism of the extraction process [8]. However, different mechanisms for elution or retention may occur, and these mechanisms are similar to those in column liquid chromatography mechanism. So far, the partitioning mechanism and/or adsorption mechanism are demonstrated to be the suitable mechanism for solid-phase extraction $[1,8]$.

SPE sorbents should have some properties to achieve significant results, such as high contact surface area to increase the loading ability, selectivity, and reduce the risk of losing the target analyte. In addition, they should have high stability toward elevated temperature and solvents that used in the extraction steps. Moreover, an excellent permeability to reduce the analysis time and backpressure when high flow is applied, are required. And they do not degrade during the storage periods [9-10].

Nowadays, there are a variety of solid-phase extraction sorbents that have been used according to the analyte target. Several examples of these sorbents are, (i) silica based; such as octadecyl bonded silica, octyl bonded silica, and butyl dimethyl bonded silica, and (ii) copolymers or crosslinked polymers depending on the sorbent material properties, which can be hydrophobic, hydrophilic, ion exchange, and mixed-mode copolymers [11].

Monolithic materials were used in the last decades as an innovative and valued generation of polymers that could be utilized in a wide range of applications. However, they could be prepared easily inside mold (s) that contain a heterogeneous or homogenous mixture. Monolithic materials morphology can be seen as a large interconnected pores or channels, consequently, these channels permit using high flow rates with suitable back pressures [12]. The appropriate surface area with significant convective mass-transfer led to consider the organic monolithic materials as ideal media to separate large molecules, for example, proteins, peptides, nucleic acids, and synthetic polymers [13-16].

The key factor for significant extraction is choosing appropriate solid phase materials. Currently, SPE materials could be selected based on the properties of the sample and the sorbent for retaining the interested sample or analyte and eluting the interfering materials [17]. This work aims to prepare a solid-phase sorbent based on a monolithic polymer that was investigated using in situ polymerization inside a glass microchip and borosilicate tube for pre-concentration of proteins.

\section{- EXPERIMENTAL SECTION}

\section{Materials}

All chemicals were purchased from Sigma-Aldrich, Poole, UK, and Fisher Scientific, Loughbrouh 3(trimethoxysilyl) propylmethacrylate ( $\gamma$-MAPS), glycidyl methacrylate, stearyl methacrylate, ethylene glycol dimethacrylate, proteins, 2,2-dimethoxy-2phenyl acetophenone, ammonium acetate, acetonitrile, sodium phosphate dibasic. 1-propanol, methanol, acetic acid, Acetone, sodium hydroxide, hydrochloric acid. Milli-q water $18 \mathrm{~m} \Omega$ was used in all experiments.

Stainless steel union $1 / 8$ " to $1 / 16$ " adapter (Kinesis, Cambs, UK), borosilicate tube (1.5 mm I.D and $3.0 \mathrm{~mm}$ O.D) (Smith Scientific, Kent, UK), polyetheretherketone (PEEK) tubing (Thames Restek Ltd., Saunderton, UK), microtight adapter (Kinesis, Cambs, UK), glass syringe (SGE, Kinesis, Cambs, UK), glass microchip B-270 crown glass (SKAN) UK were used for the preparation of the SPE sorbent.

\section{Instrumentation}

The instruments used were FT-IR 380 spectra (Thermo Scientific, Hemel Hempstead, UK), syringe pump (Bioanalytical System Inc., USA), scanning electron microscope images (Zeiss EVO 60 USA), UV light lamp (Cambridge UK), stirrer VWR (West Chester, PA, USA), HPLC-UV system (20 A Shimadzu, USA), BrunauerEmmett-Teller (BET) model (Surface Area and Porosity Analyser, Micromeritics Ltd., DunsTable, UK), C4 phenomenex aeris wide pore column, $2.1 \times 100 \mathrm{~mm}$ packed with silica particles (size $3.6 \mu \mathrm{m}$ ) (USA).

\section{Procedure}

\section{Fabrication of the monolithic materials}

Silanization step [18]. In the first step, the molds were washed with acetone, then by water. After that, the activation of the inner surface of the molds was achieved by pumping the sodium hydroxide solution $(0.2 \mathrm{M})$ at 


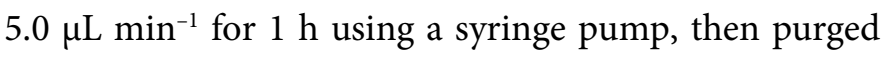
with water. Hydrochloric acid solution $(0.2 \mathrm{M})$ was pumped at $5.0 \mu \mathrm{L} \mathrm{min}{ }^{-1}$ for $1 \mathrm{~h}$, then flushed with water and ethanol. The final step was silanized the molds using 3 -(trimethoxysilyl) propylmethacrylate ( $\gamma$-MAPS) $20 \%$ in ethanol at $\mathrm{pH}$ of 5.0 that was adjusted with acetic acid through pumping at $5.0 \mu \mathrm{L} / \mathrm{min}$ for $1 \mathrm{~h}$. The molds were dried with nitrogen gas and left for $12 \mathrm{~h}$; then, the molds will be ready for in-situ polymerization.

In-situ polymerization of the monolith [19]. The photo polymerization reaction was utilized to investigate the formation of the monolith inside the molds at room temperature. The preparation method was based on Ueki et al. [19] method with some modifications. The polymerization mixture contains two monomers of stearyl methacrylate and glycidyl methacrylate with the ratio of 70:30. The crosslinker used was ethylene glycol dimethacrylate, while 2,2-dimethoxy-2-phenyl acetophenone was used as an initiator $(0.1 \%$ corresponding to the monomers).

The binary porogenic solvent consisted of methanol and 1-propanol was used with the ratio of 40:60, respectively, to dissolve monomers, crosslinker, and initiator. After dissolving all the components, an ultrawave sonicator was used to sonicate the mixture for $10 \mathrm{~min}$. The next step was removing the oxygen from the mixture by purging with nitrogen stream for $5 \mathrm{~min}$.

The molds were filled with the polymerization mixture using a syringe then closed from both sides and exposed to UV light lamp for UV polymerization at $365 \mathrm{~nm}$ for anticipated irradiation time $(23 \mathrm{~min}$ for borosilicate tube and $18 \mathrm{~min}$ for microchip). The final step was flushing the polymer with ethanol followed by water to eliminate any residual starting materials.

\section{Solid-phase extraction for pre-concentration}

The prepared monolithic sorbent was used for preconcentration of proteins. However, the performance of the monolithic sorbent was evaluated using albumin from chicken egg white cytochrome $\mathrm{C}$ from bovine heart, human insulin, myoglobin from horse heart, $\beta$ lactoglobulin from bovine milk, apo-transferrin human, and lysozyme from the chicken egg white. All the proteins used were standard proteins. $10 \mu \mathrm{M}$ of each protein was prepared by dissolving in $100 \mathrm{mM}$ ammonium acetate at room temperature around $20^{\circ} \mathrm{C}$.

The procedure of the pre-concentration was based on the methods published elsewhere [20] with some modifications. Initially, the monolithic sorbent was conditioned by pumping $500 \mu \mathrm{L}$ acetonitrile. After that, it was equilibrated using $500 \mu \mathrm{L}$ sodium phosphate dibasic at a suitable $\mathrm{pH}$ for each protein. The next step was loading the protein sample by pumping $500 \mu \mathrm{L}$ of proteins, and then the solid phase sorbent was washed with $500 \mu \mathrm{L}$ milli-q water. The final step was eluting the protein using $250 \mu \mathrm{L}$ 30:70 acetonitrile and sodium phosphate dibasic.

\section{Microchip devise for pre-concentration}

The microchip has been fabricated for preconcentration of proteins. The design of the chip contains three glass layers with the thickness of each layer is $3 \mathrm{~mm}$, while the length and width are 30 and $15 \mathrm{~mm}$, respectively.

The first layer consists of a channel with the dimension of $1 \mathrm{~mm}$ width, $5 \mathrm{~mm}$ length, and $150 \mathrm{~mm}$ depth. In addition, it contains two access holes with a diameter of $1.5 \mathrm{~mm}$. The second layer consists of the hole with the diameter of $6.5 \mathrm{~mm}$ and $1 \mathrm{~mm}$ in depth. The third layer consists of a channel with $5 \mathrm{~mm}$ length and 1 $\mathrm{mm}$ width, and $150 \mathrm{~mm}$ with two access holes $(1.5 \mathrm{~mm})$. All the layers have been prepared thermally using a custom-made oven at $585^{\circ} \mathrm{C}$ for $3 \mathrm{~h}$.

\section{- RESULTS AND DISCUSSION}

\section{Investigation of Strong Cationic Exchange/Reversed Phase Sorbent for Pre-concentration of Proteins}

Organic monolith could be regarded as appropriate sorbent materials because these materials do not need frit

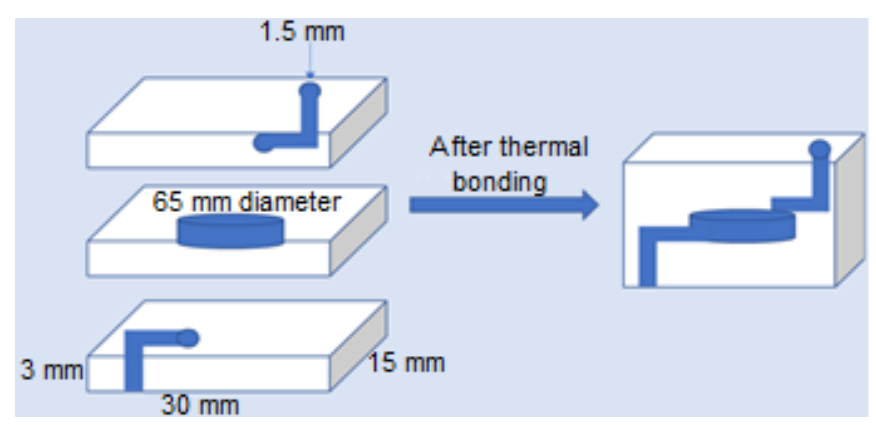

Fig 1. Microchip devise for pre-concentration 
fabrication or packing. In addition, they are easily prepared. Therefore, the prepared solid-phase sorbent was changed to strong cationic exchange/reversed phase (SCX/RP) sorbent by sulfonation of epoxy ring [21] on the surface of the monolith. The FT-IR technique was used to characterize the formation of the monolith and open epoxy ring and the transformation to $\mathrm{SO}_{3} \mathrm{Na}$ group, which could be utilized for strong cationic exchange. From the FT-IR spectrum, it can be noticed that several main prominent peaks could be used to confirm the formation of the monolithic sorbent as summarized in Table (1).

The prepared sorbent was for the pre-concentration of proteins. As mentioned elsewhere, the organic monoliths do not suffer from residual silanol interaction problems; consequently, it could be used over the wide $\mathrm{pH}$ range [23]. Therefore, the SCX/RP monolithic columns were used for the pre-concentration of the proteins with high $\mathrm{pH}$ value according to the $\mathrm{pI}$ of the protein. So far, the interfering materials could be removed, and lower detection limits could be achieved.

\section{The Morphological Properties of the SCX/RP Sorbent}

The morphological properties for the SCX/RP sorbent have been investigated using a SEM and BET analyzer. The data exhibited that the solid phase sorbent has an average surface area of $71 \mathrm{~m}^{2} / g$. This surface area could provide sufficient interactions between proteins and the functional groups on the sorbent surface due to the micro and mesopores. In addition, the average pore size was $8.13 \mathrm{~nm}$, which allows the sample molecules to move through the sorbent with a suitable backpressure. The morphology of the sorbent is shown in Fig. 2.

\section{Pre-Concentration of Proteins Using Solid Phase Sorbent that was Fabricated inside the Borosilicate Tube}

The SCX/RP monolithic sorbent has been used for pre-concentration of proteins. Eight standard proteins that differ in molecular weight and isoelectric point (pI), as shown in Table 2, have been used for the preconcentration study.

The pre-concentration method was adapted from the method published elsewhere [26]. The process consisted of several different steps. Initially, conditioning of the sorbent was performed by pumping $500 \mu \mathrm{L}$ acetonitrile using syringe pump and discard it. This process was followed by equilibrating with $500 \mu \mathrm{L}$ of $55 \mathrm{mM}$ $\mathrm{Na}_{2} \mathrm{HPO}_{4}$ at suitable $\mathrm{pH}$ for each protein. The next step was loading the sample by pumping $600 \mu \mathrm{L}$ of proteins. After that, the sorbent was washed using $500 \mu \mathrm{L}$ of milli-q water. The Final step was eluting the proteins using $300 \mu \mathrm{L}$ of 20:80 ACN (0.1\% TFA)/ $\mathrm{Na}_{2} \mathrm{HPO}_{4}$. The flow rate was $10 \mu \mathrm{L} \mathrm{min}^{-1}$ for all the steps except the sample loading step which was $5 \mu \mathrm{L} \mathrm{min}^{-1}$ to allow more time for proteins to interact with the sorbent.

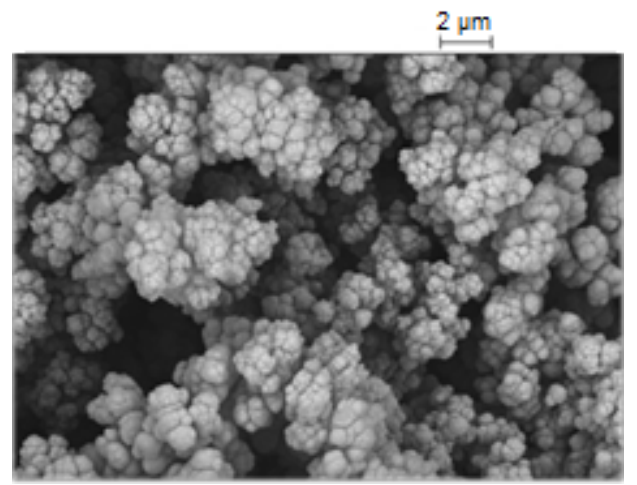

Fig 2. SEM images of the sorbent

Table 1. The FT-IR data for the main peaks of the co-polymer and the monomers before and after ring opening reaction

\begin{tabular}{|c|c|c|c|c|c|c|}
\hline Monomers/Polymers & $\mathrm{C}=\mathrm{O}[22]$ & $\mathrm{C}=\mathrm{C}[22]$ & Epoxy group [22] & $\mathrm{R}-\mathrm{SO}_{3}[23]$ & S-O [24] & $-\mathrm{OH}[25]$ \\
\hline GMA [22] & $1717.53 \mathrm{~cm}^{-1}$ & $1637.94 \mathrm{~cm}^{-1}$ & $907.79 \mathrm{~cm}^{-1}$ & & & \\
\hline SMA [22] & $1720.59 \mathrm{~cm}^{-1}$ & $1639.13 \mathrm{~cm}^{-1}$ & & & & \\
\hline EDMA [22] & $1716.89 \mathrm{~cm}^{-1}$ & $1637.86 \mathrm{~cm}^{-1}$ & & & & \\
\hline $\begin{array}{l}\text { GMA-co-SMA-co- } \\
\text { EDMA polymer }\end{array}$ & $1726.41 \mathrm{~cm}^{-1}$ & Disappeared & $910.07 \mathrm{~cm}^{-1}$ & & & \\
\hline $\begin{array}{l}\text { Formation of SCX/RP } \\
\text { monolithic sorbent }\end{array}$ & $1724.34 \mathrm{~cm}^{-1}$ & Disappeared & Disappeared & $1032.23 \mathrm{~cm}^{-1}$ & $995.96 \mathrm{~cm}^{-1}$ & $3600-3100 \mathrm{~cm}^{-1}$ \\
\hline
\end{tabular}


Table 2. Standard proteins utilized in the pre-concentration analysis

\begin{tabular}{llcc}
\hline No. & Proteins & Isoelectric point & Molecular weight (Da) \\
\hline 1 & Apo-Transferrin & 5.8 & 80000 \\
2 & Albumin chicken egg white & 5.3 & 42700 \\
3 & Trypsin & 4.5 & 23300 \\
4 & 3-Lactoglobulin & 5.3 & 18363 \\
5 & Myoglobin & 6.8 & 17199 \\
6 & Lysozyme & 11.35 & 14307 \\
7 & Cytochrome C & 10.2 & 12384 \\
8 & Insulin & 5.3 & 5805 \\
\hline
\end{tabular}

The efficiency of protein pre-concentration has been investigated depending on the extraction recovery percentage. HPLC-UV system was used to calculate the peak area of protein before and after pre-concentration, and then, to calculate the extraction recovery (ER) \% as shown in Eq. (1):

Extraction recovery $(\%)=($ I eluent $/ \mathrm{I}$ total $) \times 100$

where I eluent is the peak area of eluted protein, and I total is the peak area of injected protein before preconcentration. The result of the extraction recovery for each protein is shown in Table (3).

It can be seen from Table 3 that the extraction recovery was varied for each protein. However, cytochrome C, lysozyme, and myoglobin have a higher extraction recovery compared with other proteins. Basically, the mechanism of interactions is strong cationic and reverse phase interactions. Eventually, the electrostatic interaction will be more significant over other interactions, because the charged molecules have stronger electrostatic interactions in ion exchange chromatography and can be operated longer over the distances than other interactions. Cytochrome C, lysozyme, and myoglobin, according to Table 3 have higher $\mathrm{pI}$ value; therefore, these proteins could interact with the ionic exchanger more than other proteins due to higher charge density of these proteins. Therefore, more samples could interact with the solid phase sorbent and released the unwanted materials from the sample. Consequently, when these proteins are eluted in less solvent volume, the peak area will increase. The cytochrome $\mathrm{C}$ chromatograms before and after preconcentration are shown in Fig. 3 and 4.
It can be seen from the two figures that the peak intensity after the pre-concentration process increased, which indicates that SCX/RP sorbent could be used to purify, and pre-concentrate of cytochrome C. Cytchrome C was used as an example because it has higher extraction recovery compared with other proteins.

Table 3. Proteins extraction recovery using SCX/RP sorbent that fabricated inside borosilicate tube $(\mathrm{n}=3)$

\begin{tabular}{lc}
\hline Proteins & Extraction recovery (\%) \\
\hline Insulin & 28.42 \\
Cytochrome C & 86.76 \\
Lysozyme & 79.64 \\
Myoglobin & 68.13 \\
$\beta$-Lactoglobulin & 47.93 \\
Trypsin & 44.88 \\
Albumin chicken egg white & 49.41 \\
Apo-Transferrin & 35.83 \\
\hline
\end{tabular}

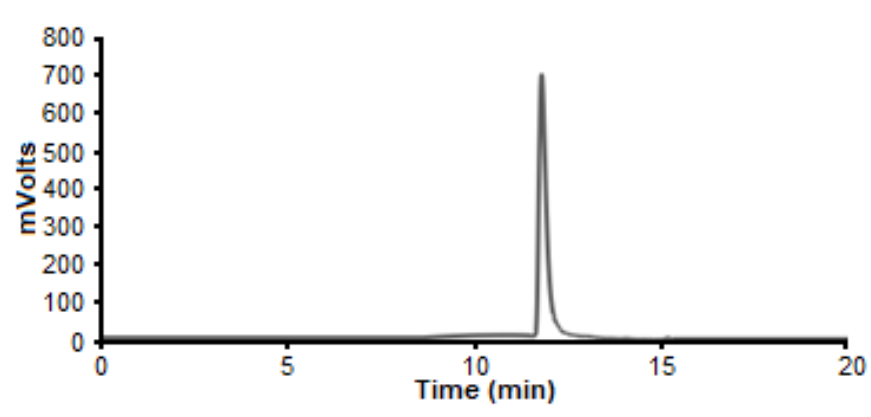

Fig 3. Cytochrome $\mathrm{C}$ chromatogram before injection to the SCX/RP sorbent using HPLC UV system (20 A Shimadzu, USA), wide pore column C4 phenomenex aeris, $2.1 \times 100 \mathrm{~mm}$ packed with silica particles (size 3.6 $\mu \mathrm{m})$, purified water/acetonitrile in the presence of $0.1 \%$ (TFA) was used as a mobile phase using gradient analysis, $0.2 \mathrm{~mL} \mathrm{~min}{ }^{-1}$ flow rate, sample injection volume $(20 \mu \mathrm{L})$, and the column temperature $40^{\circ} \mathrm{C}$ 


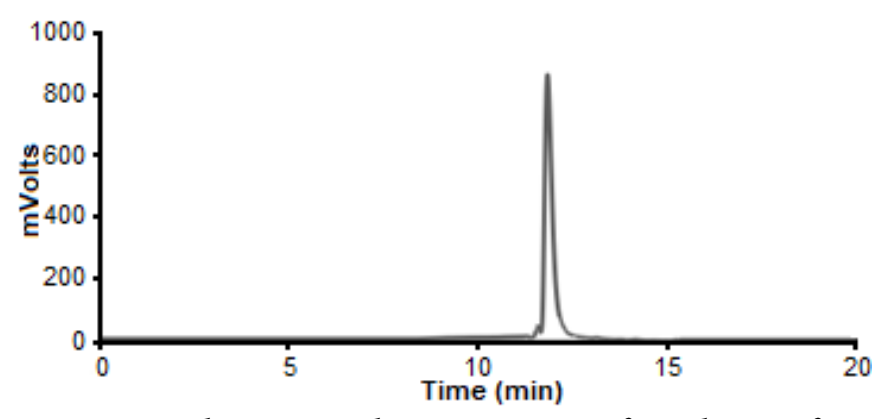

Fig 4. Cytochrome $\mathrm{C}$ chromatogram after elution from the SCX/RP sorbent using HPLC UV system (20 A Shimadzu, USA), wide pore column C4 phenomenex aeris, $2.1 \times 100 \mathrm{~mm}$ packed with silica particles (size $3.6 \mu \mathrm{m}$ ), purified water/acetonitrile in the presence of $0.1 \%$ (TFA) was used as a mobile phase using gradient analysis, $0.2 \mathrm{~mL} \mathrm{~min}^{-1}$ flow rate, sample injection volume $(20 \mu \mathrm{L})$, and the column temperature $40{ }^{\circ} \mathrm{C}$

\section{Pre-concentration of Proteins Using Glass Microchip}

The monolithic sorbent was fabricated and used as a solid-phase sorbent for proteins pre-concentration inside the glass microchip. The main reason for using the microchip was to reduce the sample and solvent volumes, ultimately lead to reducing the waste. The preconcentration process was followed the same steps as previously described, yet, the volume of the samples and solvents was reduced.

Three proteins of cytochrome C, lysozyme, and myoglobin were chosen for pre-concentration using a glass microchip because a higher recovery ratio was obtained with these proteins. So far, after conditioning the sorbent by pumping $300 \mu \mathrm{L}$ of acetonitrile using a syringe pump and it was discarded, it was equilibrated with $300 \mu \mathrm{L}$ of $55 \mathrm{mM} \mathrm{Na}_{2} \mathrm{HPO}_{4}$ at suitable $\mathrm{pH}$ for each protein. The different volumes of the protein sample, i.e., 200, 250, 300 , and $350 \mu \mathrm{L}$ were loaded in each experiment to the solid phase sorbent and washed with $300 \mu \mathrm{L}$ of milli-q water to investigate the maximum loading volume that can be used without losing of protein. The final step was eluting the proteins using $100 \mu \mathrm{L}$ of $20: 80 \mathrm{CAN}(0.1 \%$ TFA) $/ \mathrm{Na}_{2} \mathrm{HPO}_{4}$. A flow rate of $12 \mu \mathrm{L} \mathrm{min}{ }^{-1}$ was used for all steps, except for the loading step that was $6 \mu \mathrm{L} \mathrm{min}^{-1}$.

It was found that $250 \mu \mathrm{L}$ of protein samples was the maximum volume that can be utilized without losing the protein sample. The extraction recovery of the cytochrome C, lysozyme, and myoglobin using the sorbent that investigated inside the glass microchip is shown in Table 4.

It can be seen from Table 4 that the extraction recovery for the three proteins increased compared to the extraction recovery of the same proteins using the borosilicate tube as shown in Table 3. Moreover, it can be concluded that the SCX/RP sorbent prepared inside the glass microchip could be utilized for the preconcentration of proteins.

The native state of protein before and after the preconcentration process was investigated using MS spectrometer, the results showed that the protein still in the native state without any change as given in Fig. 5 .

Table 3. The extraction recovery ratio for the proteins using SCX/RP sorbent that fabricated inside the glass microchip $(\mathrm{n}=3)$

\begin{tabular}{lc}
\hline Proteins & Extraction recovery (\%) \\
\hline Cytochrome C & 98.39 \\
Lysozyme & 93.15 \\
Myoglobin & 90.97 \\
\hline
\end{tabular}

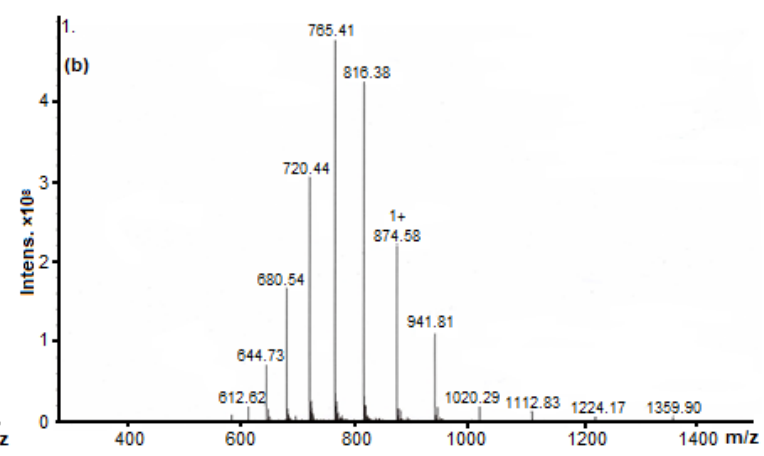

Fig 5. Mass spectra of cytochrome c (a) before and (b) after the pre-concentration process 


\section{Evaluation of Monolithic Sorbent Performance in Pre-concentration}

The extraction performance for the solid phase sorbent fabricated inside the microchip device was evaluated using the reproducibility and long-term stability. Three proteins that have higher extraction recovery, cytochrome $\mathrm{C}$, lysozyme, and myoglobin, were used in this step. Batch-to-batch reproducibility was calculated by extracting these proteins for three times using a different microchip, while run-to-run reproducibility was evaluated through extracting these proteins for three times utilizing the same microchip. The evaluation results for the solid phase sorbent are shown in Table 5.

It can be seen from Tables 5 that the extraction reproducibility using microchip was achieved due to the acceptable range of RSD\% values, which could be due to the low volume of the sample that loaded to the solid phase sorbent. Consequently, it will reduce the extraction error and improve performance.

It was found that the SCX/RP monolithic sorbent could be used for several times due to the stability of the sorbent with the time. Therefore, it could be used for 15 times when it was prepared inside the borosilicate tube. While, it could be utilized for 9 times when it was investigated inside the microchip.

Moreover, the lifetime for the monolithic sorbent was examined. The results showed that it was 20 days for the solid phase sorbent that was prepared inside the borosilicate tube, by calculating the back pressure of the experiment each time. After 20 days, the borosilicate tube was failed to keep the same performance. Therefore, it was not used after 20 days. These results were carried out for the sorbents that were stored in a mixture of water and acetonitrile with the ratio of 50:50.

Table 5. The RSD for the extraction recovery for the batch-to-batch, and for the run-to-run analysis $(n=3)$

\begin{tabular}{lccc}
\hline & \multicolumn{3}{c}{ RSD (\%) } \\
\cline { 2 - 4 } & Cytochrome C & Myoglobin & Lysozyme \\
\hline Batch-to-Batch & 1.82 & 3.19 & 3.02 \\
Run-to-Run & 2.13 & 1.95 & 2.05 \\
\hline
\end{tabular}

\section{- CONCLUSION}

A strong cationic/reversed phase monolithic sorbent was successfully prepared inside a glass microchip device and borosilicate using UV polymerization method. The final product was used as a solid phase extraction sorbent for the pre-concentration of proteins. Various proteins with different isoelectric point and molecular weight have been investigated. The results showed that the higher extraction recovery was obtained for three proteins cytochrome C, lysozyme, and myoglobin compared with the other proteins using the sorbent that was prepared inside a borosilicate tube. These three proteins have been chosen for pre-concentration test using the glass microchip. The extraction recovery for these proteins showed a significant increase compared to the same extraction recovery for the same proteins using the borosilicate tube. According to the RSD\% value of extraction recovery of proteins using the SCX/RP sorbent that was fabricated inside the glass microchip, it can be concluded that the sorbent can be used for the pre-concentration of proteins.

\section{- REFERENCES}

[1] Schley, C., Swart, R., and Huber, C.G., 2006, Capillary scale monolithic trap column for desalting and preconcentration of peptides and proteins in one- and two-dimensional separations, J. Chromatogr. A, 1136 (2), 210-220.

[2] Slabospitskaya, M.Y., Vlakh, E.G., Saprykina, N.N., and Tennikova, T.B., 2009, Synthesis and investigation of a new macroporous monolithic material based on an $N$-hydroxyphthalimide ester of acrylic acid-co-glycidyl methacrylate-co-ethylene dimethacrylate terpolymer, J. Appl. Polym. Sci., 111 (2), 692-700.

[3] Yu, C., Davey, M.H., Svec, F., and Fréchet, M.J., 2001, Monolithic porous polymer for on-chip solidphase extraction and preconcentration prepared by photoinitiated in situ polymerization within a microfluidic device, Anal. Chem., 73 (21), 50885096. 
[4] Lingeman, H., and Hoekstra-Oussoren, S.J.F., 1997, Particle-loaded membranes for sample concentration and/or clean-up in bioanalysis, J. Chromatogr. B, 689 (1), 221-237.

[5] Ulrich, S., 2000, Solid-phase microextraction in biomedical analysis, J. Chromatogr. A, 902 (1), 167194.

[6] Arrua, R.D., Moya, C., Bernardi, E., Zarzur, J., Strumia, M., and Igarzabal, C.I.A., 2010, Preparation of macroporous monoliths based on epoxy-bearing hydrophilic terpolymers and applied for affinity separations, Eur. Polym. J., 46 (4), 663-672.

[7] Armenta, J.M., Gu, B., Humble, P.H., Thulin, C.D., and Lee, M.L., 2005, Design and evaluation of a coupled monolithic pre-concentrator-capillary zone electrophoresis system for the extraction of immunoglobulin $G$ from human serum, $J$. Chromatogr. A, 1097 (1-2), 171-178.

[8] Wei, Y., Chen, X., Yang, S.C., Lv, Q.H., Ye, F.G., and Zhao, S.L., 2014, Preparation and characterization of polymer solid-phase extraction monolith immobilized metal affinity ligands, Chin. J. Anal. Chem., 42 (4), 495-500.

[9] Płotka-Wasylka, J., Szczepańska, N., de la Guardia, M., and Namieśnik, J., 2016, Modern trends in solid phase extraction: New sorbent media, TrAC, Trends Anal. Chem., 77, 23-43.

[10] Gilart, N., Borrull, F., Fontanals, N., and Marcé, R.M., 2014, Selective materials for solid-phase extraction in environmental analysis, Trends Environ. Anal. Chem., 1, e8-e18.

[11] Andrade-Eiroa, A., Canle, M., Leroy-Cancellieri, V., and Cerdà, V., 2016, Solid-phase extraction of organic compounds: A critical review (Part I), TrAC, Trends Anal. Chem., 80, 641-654.

[12] Arrua, R.D., Strumia, M.C., and Alvarez Igarzabal, C.I., 2009, Macroporous monolithic polymers: Preparation and applications, Materials, 2 (4), 2429-2466.

[13] Oberacher, H., and Huber, C.G., 2002, Capillary monoliths for the analysis of nucleic acids by highperformance liquid chromatography-electrospray ionization mass spectrometry, $\operatorname{Tr} A C$, Trends Anal. Chem., 21 (3), 166-174.
[14] Tanaka, N., Nagayama, H., Kobayashi, H., Ikegami, T., Hosoya, K., Ishizuka, N., Minakuchi, H., Nakanishi, K., Cabrera, K., and Lubda, D., 2000, Monolithic silica columns for HPLC, Micro-HPLC, and CEC, J. High. Resolut. Chromatogr., 23 (1), 111116.

[15] Trojer, L., Lubbad, H., Bisjak, P., Wieder, W., and Bonn, K., 2007, Comparison between monolithic conventional size, microbore and capillary $\operatorname{poly}(p-$ methylstyrene-co-1,2-bis( $p$-vinylphenyl)ethane) high-performance liquid chromatography columns: Synthesis, application, long-term stability and reproducibility, J. Chromatogr. A, 1146 (2), 216-224.

[16] Jančo, M., Sýkora, D., Svec, F., Fréchet, J.M.J., Schweer, J., and Holm, R., 2000, Rapid determination of molecular parameters of synthetic polymers by precipitation/redissolution highperformance liquid chromatography using "molded" monolithic column, Journal of Polymer Science Part A: Polymer Chemistry, 38 (15), 27672778.

[17] Huck, C.W., and Bonn, G.K., 2000, Recent developments in polymer-based sorbents for solidphase extraction, J. Chromatogr. A, 885 (1-2), 5172.

[18] Peterson, D.S., Rohr, T., Svec, F., and Fréchet, J.M., 2003, Dual-function microanalytical device by in situ photolithographic grafting of porous polymer monolith: Integrating solid-phase extraction and enzymatic digestion for peptide mass mapping, Anal. Chem., 75 (20), 5328-5335.

[19] Ueki, Y., Umemura, T., Li, J., Odake, T., and Tsunoda, K., 2004, Preparation and application of methacrylate-based cation-exchange monolithic columns for capillary ion chromatography, Anal. Chem., 76 (23), 7007-7012.

[20] Alzahrani, S., 2012, Investigation of monolithic materials for protein sample preparation, Dissertation, Department of Chemistry, University of Hull, United Kingdom.

[21] Paul, S., and Rånby, B., 1976, Methyl methacrylate (MMA)-glycidyl methacrylate (GMA) copolymers. 
A novel method to introduce sulfonic acid groups on the polymeric chains, Macromolecules, 9 (2), 337-340.

[22] Safa, K.D., and Nasirtabrizi, M.H., 2006, Ring opening reactions of glycidyl methacrylate copolymers to introduce bulky organosilicon side chain substituents, Polym. Bull., 57 (3), 293-304.

[23] Wang, L., Su, Y., Zheng, L., Chen, W., and Jiang, Z., 2009, Highly efficient antifouling ultrafiltration membranes incorporating zwitterionic poly([3(methacryloylamino)propyl]-dimethyl(3sulfopropyl) ammonium hydroxide), J. Membr. Sci., 340 (1-2), 164-170.

[24] Liu, Y., and Laskin, A., 2009, Hygroscopic properties of $\mathrm{CH}_{3} \mathrm{SO}_{3} \mathrm{Na}, \mathrm{CH}_{3} \mathrm{SO}_{3} \mathrm{NH}_{4}, \quad\left(\mathrm{CH}_{3} \mathrm{SO}_{3}\right)_{2} \mathrm{Mg}$, and
$\left(\mathrm{CH}_{3} \mathrm{SO}_{3}\right)_{2} \mathrm{Ca}$ particles studied by micro-FTIR spectroscopy, J. Phys. Chem. A, 113 (8), 1531-1538.

[25] Refat, M.S., Ismail, L.A., and Adam, A.M.A., 2013, Synthesis and structural characterization of chargetransfer complexes derived from three symmetrically substituted 4,4'-bis-(1,3,5triazinylamino)stilbene-2, $2^{\prime}$-disulfonate derivatives with some $\pi$-acceptors. Part one: Chloranilic acid, Int. J. Chem. Sci., 11 (4), 1647-1658.

[26] Miyazaki, S., Morisato, K., Ishizuka, N., Minakuchi, H., Shintani, Y., Furuno, M., and Nakanishi, K., 2004, Development of a monolithic silica extraction tip for the analysis of proteins, J. Chromatogr. A, 1043 (1), 19-25. 